\title{
Searching online for health-related information by people suffering from respiratory allergy and asthma: the results of a survey study
}

The authors declare no financial disclosure

\begin{abstract}
Introduction: The objective of the study was to compare online behaviour in groups of persons suffering from respiratory allergy and/or asthma and in the reference group.

Material and methods: Comparative analysis of two independent questionnaire studies. Study A was carried out in the Masovian Voivodeship, Poland in 2013. As many as 1,728 questionnaires were collected and 51 respondents were selected for analysis (study A, reference group). Study B was carried out in 2014 in a group of 59 patients of the outpatient allergy clinic.

Results: More than $92 \%$ of the general population (study A) declared that they used the Internet to search for health-related information, health protection, while in the group of patients (study B) the same was declared by $97 \%$. Both studies showed that more than $74 \%$ of respondents looked for online information on a specific disease $(p>0.05)$. Information on how other persons cope with similar health issues was searched by $20 \%$ (study A) and $33 \%$ (study B) of respondents. Advice on different methods of treatment of a given disease was sought by $40 \%$ and $51 \%$ of respondents, respectively. Nearly $51 \%$ of respondents in study A and $56 \%$ of subjects in study B searched online for health information when they did not feel well or were sick.

Conclusions: Both in the group of chronically ill persons and in the reference group, it is common to search online for health-related information. Persons suffering from respiratory allergy and/or asthma verified the physician's diagnosis on the Internet much more often than did the reference group.
\end{abstract}

Key words: asthma, allergy, world wide web, consumer health information, self-diagnosis

Adv. Respir. Med. 2017; 85: 87-96

\section{Introduction}

Owing to the progress of civilisation and the development of information and communication technologies, $63 \%$ of adult Poles use the Internet regularly, i.e. at least once a week. According to data from the Centre for Public Opinion Research, the number of Internet users has increased threefold since 2002. Young people (18-24 years old) and those with tertiary education form the largest groups - combined over 94\%. Along with the rise in the number of Internet users, as many as $88 \%$ of them use dedicated online health services when seeking information on health, diseases or methods of treatment. Physicians and representatives of health care institutions form the second source of knowledge of health (73\%) after the Internet. The older the age, the lower the number of Internet users [1], along with the percentage of those searching for health information on the Internet [2]. In 2008 in the United States of America (USA), as many as 8 out of 10 Internet users searched for health information online ( $61 \%$ of adults). Every second Internet

Address for correspondence: Anna Kłak, Department of Prevention of Envinronmental Hazards and Allergology, Medical University of Warsaw, Poland,

e-mail: anna.klak@wum.edu.pl

DOI: 10.5603/ARM.2017.0015

Received: 02.11.2016

Copyright (C) 2017 PTChP

ISSN 2451-4934 
user admits that online information influenced a decision on disease treatment or change of lifestyle [3]. According to the results published by Hesse (2012), 'Dr. Google' is the most frequently used source of information about health in the USA [4]. Hesse describes this trend as positive. He stresses, however, that health care should aim at improving credibility and reliability of the information published online, so that it does not mislead the patient [4].

Social network technologies make it possible to use an Internet-based platform to communicate about health and disease, to share experiences about care, and to increase medical knowledge. Internet platforms that use social media technologies, such as Wikipedia, Facebook, LinkedIn, YouTube, and Twitter, have become highly popular among millions of people worldwide [3-5]. People with chronic diseases who use online communication tools become more acquainted, are likely to feel better socially supported and empowered, and have improved behavioural and clinical outcomes compared to nonusers [5]. The use of patient-centred Web technologies for chronic disease self-management requires greater understanding, particularly in terms of the associated costs and benefits. New knowledge, social technologies and engagement techniques, when effectively translated, will result in novel approaches to empowering, engaging, and educating older adults suffering from chronic diseases [6].

The results of studies carried out in the USA prove that online information available at patient-dedicated Internet portals is extremely useful for those suffering from chronic diseases (or their families). Most often it helps in understanding the disease and coping with it [7]. The results showed the improvement of health and change in lifestyle in a group of persons who used patient-dedicated portals to search for health-related information. At the same time it was shown that persons who used the Internet to obtain health information tended to cancel appointments [8].

Allergy and asthma are of great significance from the health policy perspective as they concern $30 \%$ of the population in highly developed countries, have a lifelong course and start in early childhood. Globally, 300 million people suffer from asthma and about 200-250 million from food allergies [9]. In the outpatient part of the study Epidemiology of Allergic Disease in Poland (ECAP), the incidence of asthma diagnosis depending on the age of the respondent amounted to: children 6-7 years of age: $11 \%$, children 13-14 years of age: $11 \%$, adults $20-44$ years of age: $9 \%$ [10]. As many as $25 \%$ of those under 30 years of age who suffer from allergy require permanent physician supervision. Due to the chronic nature of allergic diseases, the quality of life of patients is lower [11]. It should be noted that the medical awareness of patients, in particular those chronically ill, is more often shaped by information posted on the Internet. Until now 'the patient - as a traditional user of the healthcare system' acted as a passive recipient of medical services, whereas now the 'contemporary patient - as an Internet user' is more active and more demanding towards medical personnel and in obtaining medical information.

The subsequent aim of the study was to compare online behaviour (searching for health-related information) in a group of patients with respiratory allergies and/or asthma within the reference group.

\section{Material and methods}

The frequency, motives and attitude towards health information obtained from the Internet were also evaluated, as well as defining the source of health information, including positioning the Internet as an important source of medical expertise.

\section{Material}

The study group comprised 20-44-year-old adults. The basis of the range was the high prevalence rate of allergies and/or asthma in this age group and the highest participation of this age group in using the Internet, compared to the general population. The analysed subgroups were similar in terms of age and sex, and there were no statistically significant differences in terms of education $(\mathrm{p}=0.076)$ or financial status $(\mathrm{p}$ $=0.123$ ). As assumed, the subgroups differed in terms of asthma occurrence as well as symptoms of the upper respiratory tract allergies ( $\mathrm{p}<$ 0.001 ). The characteristics of the study group are presented in Table 1.

\section{Research method}

Comparative analysis of two independent questionnaire studies, carried out with the use of questionnaires including common blocks of questions.

\section{Study A}

The first study (hereinafter referred to as study A) was carried out in the Masovian Voivodeship (Poland) in May/June 2013. This questionna- 
Table 1. Characteristics of the study group

\begin{tabular}{|c|c|c|}
\hline & $\begin{array}{l}\text { Study } A-\text { reference } \\
\quad \text { group, } \mathrm{n}=51\end{array}$ & $\begin{array}{l}\text { Study B - asthma/ } \\
\text { /allergy, } \mathrm{n}=\mathbf{5 1}\end{array}$ \\
\hline \multicolumn{3}{|l|}{ Sex } \\
\hline Female & $54.9 \%, n=28$ & $54.9 \%, n=28$ \\
\hline Male & $45.1 \%, n=23$ & $45.1 \%, n=23$ \\
\hline \multicolumn{3}{|l|}{ Age } \\
\hline $20-24$ years & $23.5 \%, n=12$ & $23.5 \%, n=12$ \\
\hline $25-29$ years & $25.5 \%, n=13$ & $25.5 \%, n=13$ \\
\hline $30-34$ years & $21.6 \%, n=11$ & $21.6 \%, n=11$ \\
\hline $35-39$ years & $19.6 \%, n=10$ & $19.6 \%, n=10$ \\
\hline $40-44$ years & $9.8 \%, n=5$ & $9.8 \%, n=5$ \\
\hline \multicolumn{3}{|l|}{ Education } \\
\hline Primary & $2 \%, n=1$ & 0 \\
\hline Lower secondary & $2 \%, n=1$ & 0 \\
\hline Basic vocational & $5.9 \%, n=3$ & $2 \%, n=1$ \\
\hline Secondary & $35.3 \%, n=18$ & $17.6 \%, \mathrm{n}=9$ \\
\hline Tertiary & $54.9 \%, n=28$ & $80.4 \%, n=41$ \\
\hline \multicolumn{3}{|l|}{ Financial status } \\
\hline Affluent, no need to save up, even for higher expenditures & $4 \%, n=2$ & $3.9 \%, n=2$ \\
\hline Enough money for all expenditures, some can be saved & $34 \%, n=17$ & $43.1 \%, n=22$ \\
\hline Enough money for everyday expenditures, but cannot afford higher expenditures & $56 \%, n=28$ & $33.3 \%, n=17$ \\
\hline Must deny many things to have enough money for everyday expenditures & $4 \%, n=2$ & $15.7 \%, n=8$ \\
\hline Not enough money even for immediate needs & $2 \%, n=1$ & $3.9 \%, n=2$ \\
\hline \multicolumn{3}{|l|}{ Positive responses to questions: } \\
\hline $\begin{array}{l}\text { Have you experienced at any time problems with sneezing, running or congested nose } \\
\text { while not having a cold, fever or flu? }\end{array}$ & $49 \%$ & $92 \%$ \\
\hline $\begin{array}{l}\text { Have you suffered from any nasal allergic diseases, including nasal congestion caused } \\
\text { by an allergy to plant pollen (allergic rhinitis)? }\end{array}$ & $26 \%$ & $82 \%$ \\
\hline Have you taken any medicine for shortness of breath or respiratory problems? & $11.8 \%$ & $83.7 \%$ \\
\hline Have you experienced wheezes or whistles in the chest at any time during last 12 months? & $9.8 \%$ & $70 \%$ \\
\hline Have you ever suffered from asthma? & $5.9 \%$ & $85.7 \%$ \\
\hline Has the asthma been confirmed by a physician? & $16.7 \%$ & $95.2 \%$ \\
\hline \multicolumn{3}{|l|}{ Chronic diseases } \\
\hline Asthma & $3.9 \%$ & $82.4 \%$ \\
\hline
\end{tabular}

ire study was fully anonymous. The respondents were identified only by an ID number assigned for the purpose of the study.

The study group consisted of persons from 20 to 44 years of age (average age: 28.14 years, median age: 26 years). As many as 1,728 questionnaires were collected, out of which 1,720 were completed in whole. As many as 51 respondents were selected for the present analysis (simple random sampling in age and sex subgroups), who corresponded in terms of sex and age to the study group of the second study (hereinafter referred to as study B).

According to the guidelines of the Bioethics Committee of the Medical University of Warsaw, non-invasive studies (including questionnaires) of this type do not require specific ethics approvals. Written informed consent obtained from the human subjects were not necessary as the respondents only completed the questionnaire themselves. They did not undertake any anthropometric measurements nor clinical studies. 


\section{Study $B$}

Study B was carried out in 2014 at the outpatient allergy clinic of the Central University Hospital, Medical University of Warsaw (SPCSK) in Warsaw. The study group was composed of patients suffering from asthma and allergy of the upper respiratory tract, reporting for a control visit to the allergist, and/or patients reporting for skin tests and desensitisation $(n=59)$.

The study was carried out between February and April 2014. The questionnaire was distributed to patients by a nurse at the outpatient allergy clinic of SPCSK, who was trained in the study methodology. The study was fully anonymous. The study was approved by the management of SPCSK hospital. According to the guidelines of the Bioethics Committee of the Medical University of Warsaw, non-invasive studies (including questionnaires) of this type do not require specific ethics approvals. Written informed consent obtained from the human subjects was not necessary as the respondents only completed the questionnaire themselves. They did not undertake any anthropometric measurements nor clinical studies.

A group of 51 respondents was included in the study - their age and sex corresponded to the study A respondents.

\section{Research tool}

The research tool in both studies was a questionnaire developed by researchers to be completed individually by each respondent. It included 45 questions, most of which were closed-ended. The questionnaires included common sets of questions on the frequency and purpose of their Internet use, types of information on health or disease searched online, attitude towards the possibility of using the Internet, the use of medical services or health prevention solutions, use of medicines, health condition of the respondent, and characteristics of the study group.

Fragments from the following questionnaires were used in the development of the research tool for study B: International Study of Asthma and Allergies in Childhood (ISAAC), and European Community Respiratory Health Survey II (ECRHS II). Additional analyses were carried out within study B on the use of online discussion portals.

For the purpose of the article, the term 'health-related information' meant every text on health and disease published online, both by persons with a medical background (or paramedical) and those with no medical background. The Internet in the present article is understood as the various types of websites dedicated to health issues, blogs, social networking services (such as Facebook, Twitter, NK.pl, LinkedIn, Goldenline), text messages (including email, skype, other messengers), discussion forums.

\section{Statistical analysis}

Analysis of the results was carried out using the IBM SPSS programme (ver. 22). A difference $\mathrm{p}<0.05$ was considered statistically relevant.

\section{Results}

\section{Searching for health-related information}

The distribution of responses related to searches for information on the health of a respondent, health protection or medical services, was similar in both studies ( $p>0.05$ ). Over $92 \%$ of respondents in the reference group from study A declared that they used the Internet to search for information on health, health protection or medical services, while in the study B group of patients suffering from asthma and/or allergy of the upper respiratory tract, this percentage was higher, i.e. it reached $97 \%$. The most frequent answers were 'less than once a month' and 'several times a month'. 'Once a month' and 'Several times a week' were relatively frequent answers in both studies (Fig. 1).

\section{Information searched online}

In both studies, over $74 \%$ of respondents searched online for the information on a specific disease $(p>0.05)$. Every second respondent in study $B$ and every third respondent in study A searched online for an opinion about physicians. Every third respondent in study B and every fifth respondent in study A sought online information on how others cope with similar health issues. As many as $40 \%$ of respondents (study A) and $51 \%$ of respondents (study B) searched for information on different methods of treatment of a given disease. The respondents participating in study $B$ used the Internet more often to search for health-related information. Statistically significant differences were demonstrated in the case of searching online for the following: opinions about physicians ( $p<0.05$ ), opinions about healthcare institutions ( $p<0.05)$, knowledge of a specific diagnostic test ( $p<0.01)$, information on a specific drug, its effect, use and side effects $(\mathrm{p}<0.05)$ and making a physician appointment (by telephone or online) $(p=0.05)$. Detailed data are presented in Figure 2. 


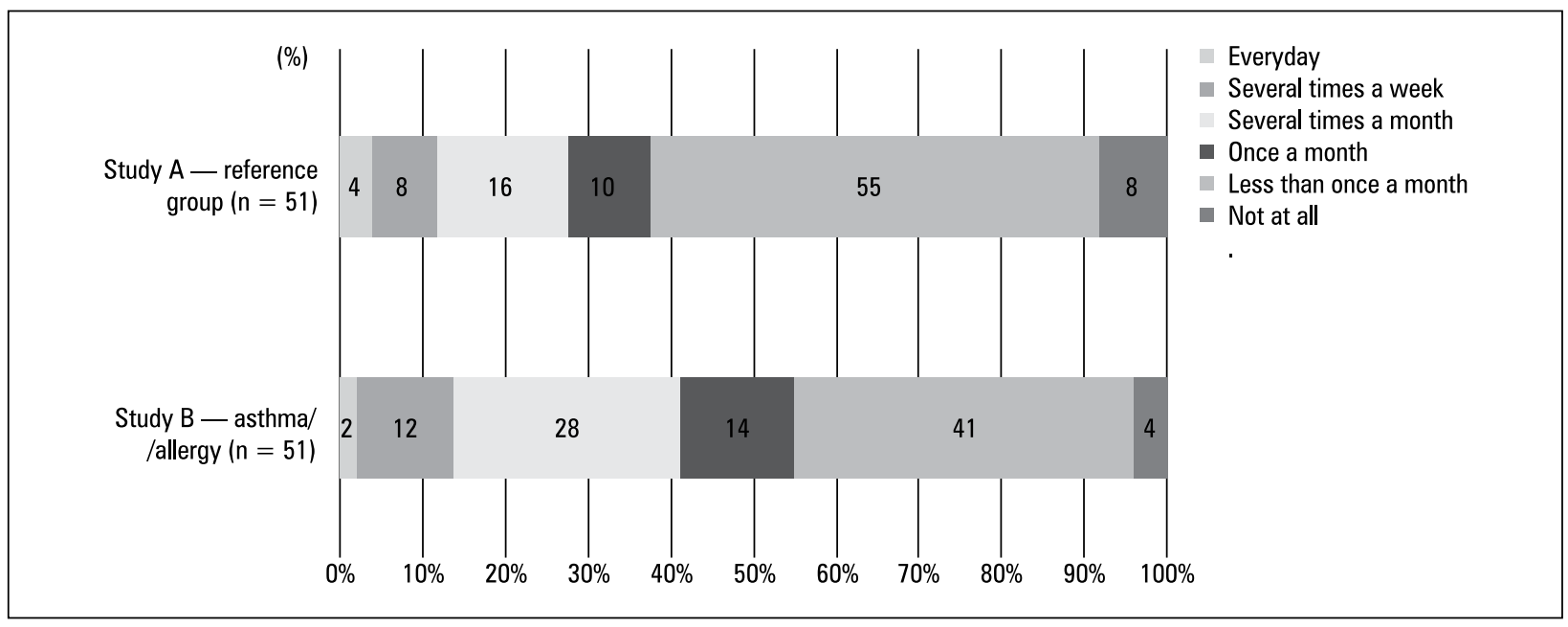

Figure 1. The use of the Internet to search for information about the health of a respondent, health protection or medical services, $n=102$

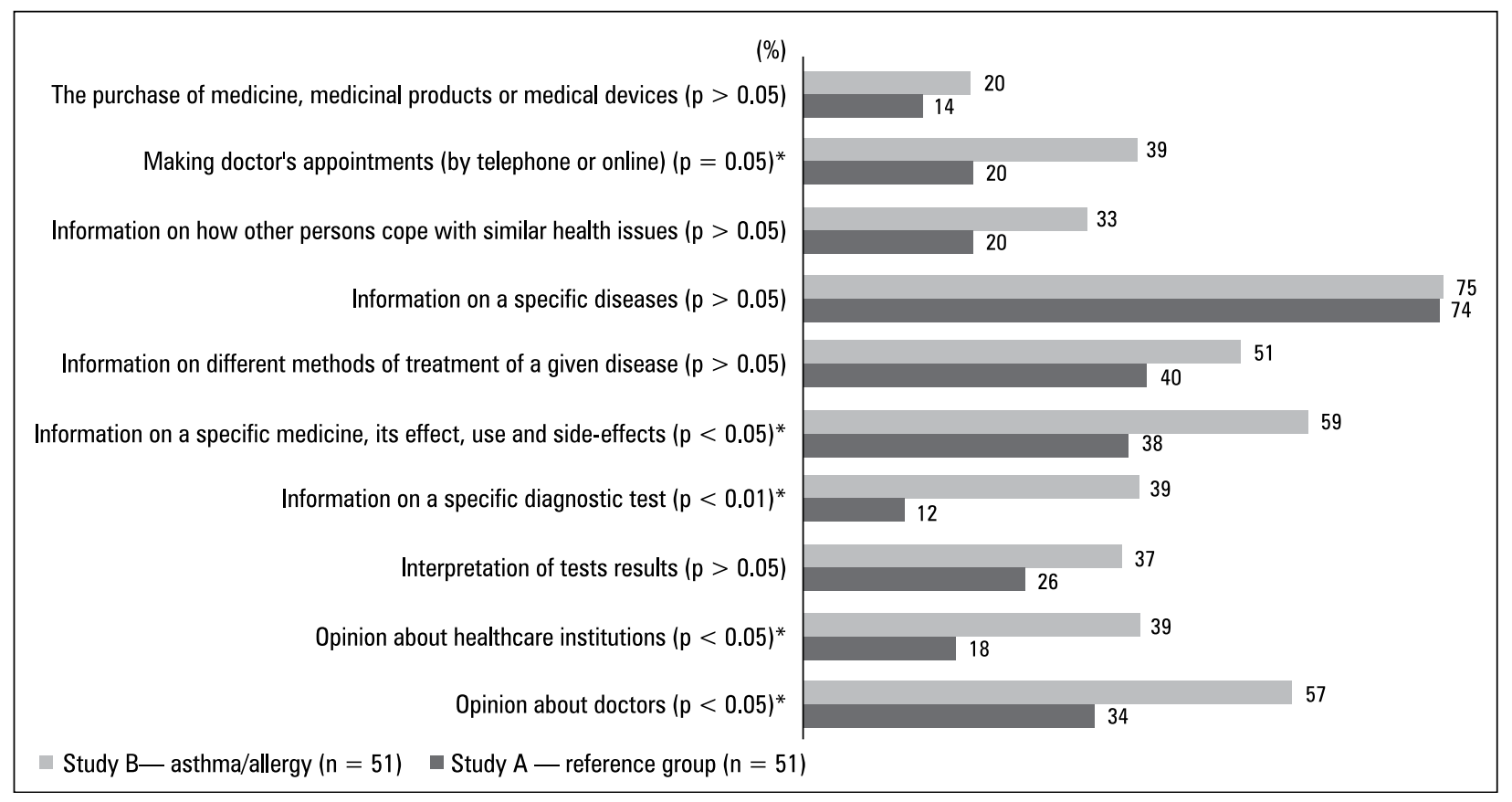

Figure 2. Information searched online for health-related information, $n=102,{ }^{*}$ statistically significant differences

\section{Motives for searching for the information online}

Unlike the respondents in study A, a significant majority of the respondents in study B agreed with the statement that they search online for an opinion about the physician they are planning to visit $(65 \%$ in relation to $35 \%$; $<<0.05)$. There are statistically significant differences between the groups ( $p>0.05$ ) in respect of various opinions about using the Internet to search for information on health status or self-treatment. Every second respondent, both in study A and study B, agreed with the opinion that they searched online for health information when feeling unwell or sick (study A: 51\%, study B: 56\%). A high percentage of positive responses was observed for the following opinion: I search for health-related information online when I do not want to or cannot see the physician: study A-43\%, study B-47\% (Table 2).

In both studies, the respondents declared more often that they do not agree with the opinion that: they consider most information about health published online credible (study A: $35.3 \%$, study B: $42 \%$ ), and they often share online their experience relating to health and treatment (study A: 84\%, study B: 79.6\%) (Table 2). 


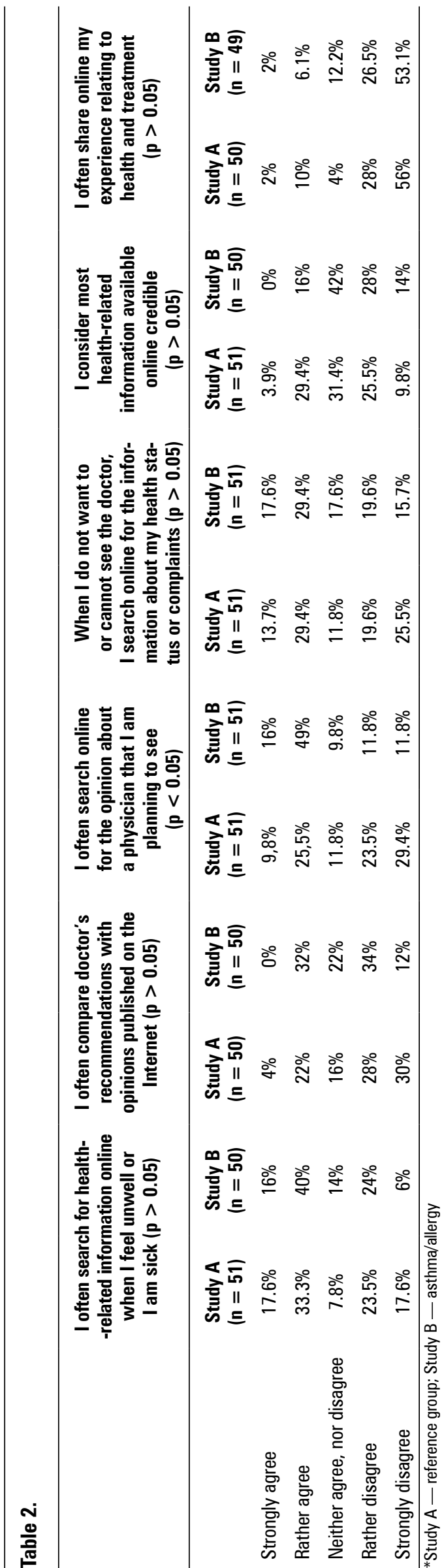

\section{Verification of physician's recommendations}

As many as $60 \%$ of respondents in study $A$ and $79 \%$ of respondents in study B $(p<0.05)$ used the Internet to verify online a physician's diagnosis and recommendations. Over 50\% of respondents in both studies $(p>0.05)$ sometimes verified the diagnosis at online discussion forums. In the reference group (study A), the respondents most often verified the physician's diagnosis and recommendations during conversations with close friends (84\%) and with other physicians (69\%), whereas in the group of patients in Study $\mathrm{B}$, the verification was done during a conversation with a close friend $(82 \%)$ and at health-dedicated websites (79\%, p > 0.05) (Figs 3A, 3B).

\section{The use of online discussion forums}

Study B underwent additional analysis. As many as $68 \%$ of respondents verified the physician's diagnosis and physician's recommendations by consulting with persons who had experienced similar health issues.

Internet portals (such as Facebook, Twitter, NK.pl, LinkedIn, Goldenline, blogs, email, Skype, other discussion forums and social networking sites) were used by $95 \%$ of respondents. As many as $31 \%$ of respondents declared that they used these types of portals to obtain additional information on a disease and/or treatment, while $11.9 \%$ of subjects admitted that they also shared their experiences relating to health and treatment online.

Every fourth respondent (25.4\%) exchanged health-related information with other persons via portals or Internet services. The following were most often mentioned: Facebook - 16.9\%, email $-6.8 \%$, Skype $-3.4 \%$, other discussion forums $-3.4 \%$, other social networking sites $-1.7 \%$. None of the respondents mentioned in this case the portals Twitter, LinkedIn, Goldenline or blogs. As many as $18.6 \%$ of respondents gave a negative answer to the question 'Do any of the persons you usually consult about your health status have a degree in medicine?', with $15.3 \%$ of respondents answering this question positively, and $16.9 \%$ of respondents replying 'I do not know'.

Among the general population in study B, $5.1 \%$ of respondents always seek online advice from persons with a medical degree when they get ill and have the possibility, and as many as $11.9 \%$ only when they cannot/do not want to see a physician. Also $11.9 \%$ of subjects indicated the response 'In the case I want to compare a physician's recommendations with opinions published 


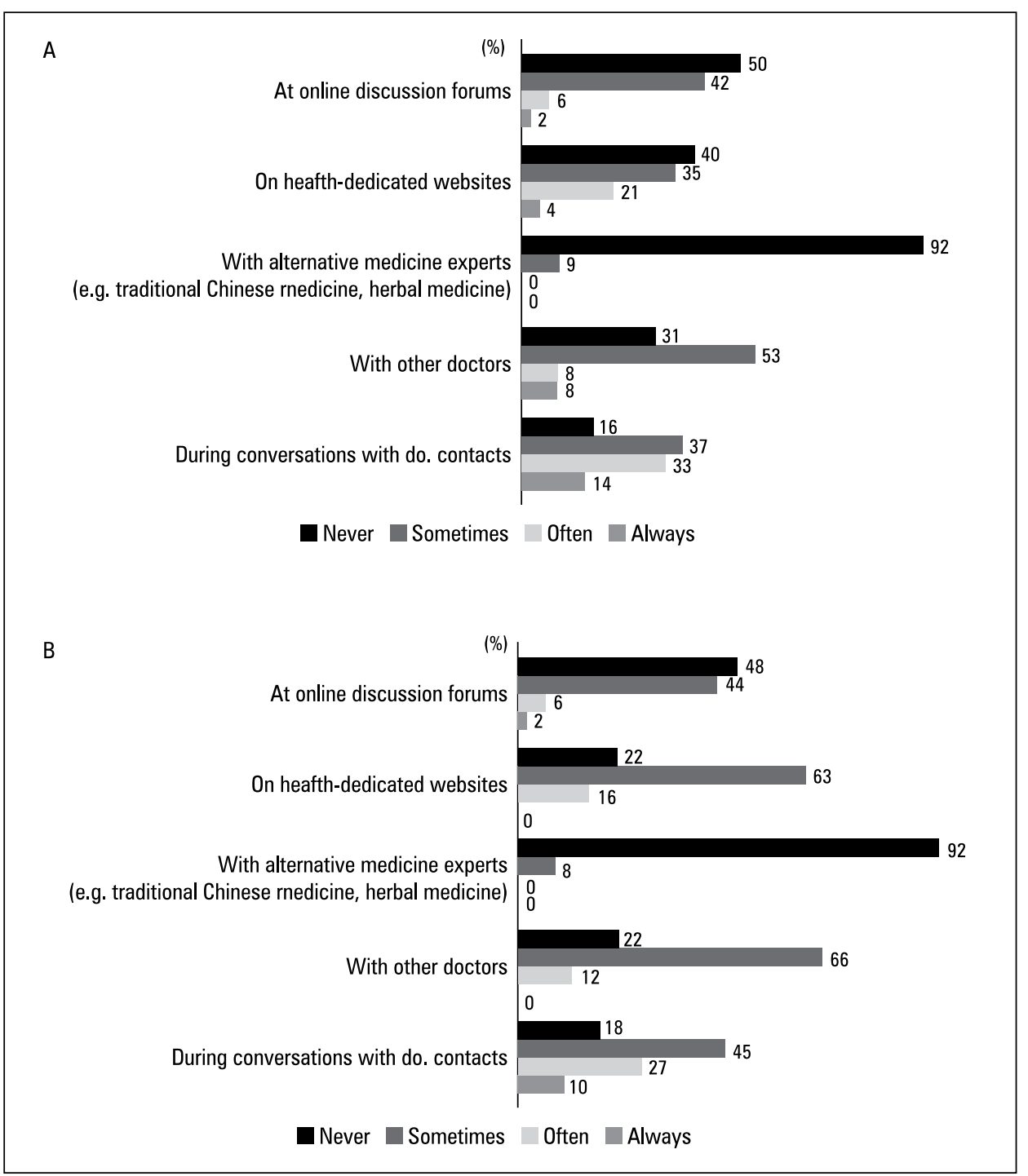

Figure 3. A - verification of physician's diagnosis in the case of disease and physician's recommendations - Study $A, n=51$; B - verification of physician's diagnosis in the case of disease and physician's recommendations - Study $B, n=51$

online', and $8.5 \%$ of respondents indicated the answer 'In the case I want to learn about alternative treatment methods for a given disease'.

\section{Discussion}

The narrow range of age of the study groups and the questionnaire nature, both, constitute a fundamental limitation in the study. The declarations of the respondents are the source of the obtained data and not the observation of their behaviour. In the case of questions on using the Internet to search for health-related information, there is a slight risk that the respondents could have hidden their true opinions. At present, searching for health-related information online and even self-diagnosis and self-treatment are not socially criticised. It could then be assumed that the data obtained within the study are not significantly affected.

Despite the small study group, the comparison of the two study groups and the wide range of questions on the use of the Internet for health purposes should be considered the strength of the study, as they make it possible to analyse different aspects of this phenomenon. Moreover, this is the first study in Poland, which makes a comparison group of adults with asthma and/ /or allergy to reference group in the search for health information on the Internet. Authors do not analyze if obtaining information is sufficient to help with compliance and adherence. This issue requires further detailed research.

According to a Polish public opinion poll relating to the image of Polish medicine carried out by Procontent Communication in 2015, in the 
group of 800 Poles aged 15-50, almost half of them (45\%) had tried medical self-diagnosis or had attempted to diagnose a relative using information available online [12]. The results also confirm the analysis made for the general population within the present study: $51 \%$ of respondents searched for health-related information online when they felt unwell or sick (56\% in the group of patients), and $43.1 \%$ of respondents searched for health information on ailments online when they did not want to or could not see a physician $(47 \%$ in the group of patients). According to the study by Procontent Communication, this is mainly due to the long waiting periods for appointments (32\%), a lack of time to visit the physician (30\%) and self-confidence in finding the correct response online (26\%) [12].

The analysis demonstrated that over $92 \%$ of respondents in the reference group and $97 \%$ in the group of patients used the Internet to search for health-related information. These outcomes are confirmed by the results of the study carried out in a group of 1,828 Brazilians by Moretti et al. [13], which indicated that $80 \%$ of the society considers the Internet to be the main source of health information. As many as $90 \%$ of the subjects searched for the information on their own health status, and 79\% - for information on the health of relatives [13]. Over $50 \%$ of respondents searched for health-related information online more often than once a week [13]. In our analysis, this percentage is significantly lower, i.e. it amounts to $12 \%$ in the general population and $14 \%$ in the group of patients [13].

In the present study, every third respondent in the general population admitted that most health-related information available online is credible, whereas this response was only given by $16 \%$ in the group of patients. $74 \%$ of respondents in the present study searched online for information on a specific disease, while information of different treatment methods for the same disease was searched by $40 \%$ (study A) and 51\% (study B) of respondents. To compare: over $50 \%$ of respondents in the Moretti [13] study searched online for the following information: quality of life, disease prevention, diet, disease symptoms. Kisilowska and Jasiewicz [14], after having conducted in 2012 a quality study in a group of 150 patients from Warsaw outpatient clinics, present different outcomes. The authors indicate that the respondents most often searched online for information on the following: the significance of different symptoms (24\%), as well as medicines and their effects (23\%), opinions about physicians (19\%; in the present study: $34 \%$ in the general population and $57 \%$ in the group of patients), home remedies and treatments (15\%), diet (12\%) and alternative medicine (7\%) [14]. In the light of the outcomes of the present studies as well as the study by Moretti et al. [13] and Kisilowska and Jasiewicz [14], it is important to notice that according to Moretti, as many as $65 \%$ of respondents declared that they changed their lifestyle after having obtained health-related information from the Internet and $48 \%$ of them admitted that they discussed the information obtained online with a physician.

Heaivilin et al. [15] present interesting results in respect to the present study, indicating that people actively search for information on health and disease on Twitter. It was shown that people very often share their health-related experience on Twitter and search for advice [15]. None of the respondents in the present study (in the group of patients) shared their health experience on Twitter. Among the social networking sites only Facebook was mentioned (16.9\%).

The study showed that the respondents of both studies tried to verify physician recommendations. They verified the diagnosis with close friends first. Analyses showed that among the general population in Poland the most common way to verify diagnoses and physician recommendations is to talk to a close friend or consult with another physician, despite the popularity of the Internet. Those patients suffering from chronic respiratory allergy and/or asthma (study B) often consulted with close friends and visited health-dedicated websites. It is worth noting that people from study B (group of chronically ill) verified the diagnosis made by a physician on the Internet much more often than those in group A (general population). Moreover, it was observed that in both study groups the respondents searched for health-related information online, even though they declared that health-related information published on the Internet is not credible in their opinion. Similar results were obtained by Duplaga [16]; in a study carried out in Poland in a group of 165 patients suffering from asthma, chronic obstructive pulmonary disease (COPD) or other diseases of the respiratory system. It is worth underlining that only $16.7 \%$ of respondents in the study by Duplaga searched for information on how other patients coped with a similar health issue [16]. In the present study this percentage was considerably higher - it amounted to $33 \%$. In the study by Duplaga, $7.3 \%$ of patients searched for 
expert opinions and $4.2 \%$ of them provided online support to other patients, while in the present study almost $12 \%$ of respondents in the group of patients shared their experiences relating to health and treatment online. These results correspond with the outcomes of studies carried out by Bundorf et al. [17], and Thackeray et al. [18]. Similarly to our study, Bundorf et al. [17] showed that persons suffering from chronic disease more often searched online for health-related information, compared to persons who did not suffer from any chronic disease $(p<0.05)$. This outcome is confirmed also in the present analysis, despite the fact that the difference was not statistically significant (respectively: $97 \%$ vs. $92.3 \%, p>$ 0.05). In the study by Thackeray [18], as in the study by Duplaga [16], a statistically significant relation was proved by the respondent declaration 'Consulted online rankings or reviews' and the occurrence of chronic disease $(49.6 \%$, $\mathrm{p}<0.001)$. Having a chronic disease increased the odds of consulting online rankings [18].

Own results and the results obtained by the authors of the quoted surveys point to the need for on-line education of people with chronic diseases. Patient education online and attention to the credibility of health information available on the Internet is very important, especially bearing in mind the results which indicate that those with serious health issues search for health-related information online in particular when they experience barriers in the healthcare system [17]. Patients suffering from asthma also need training in management of the disease. Gibson et al. [19] made a literature review in 2003 that included randomised trials of self-management education in adults with asthma over 16 years of age. It was shown that education about self-management of asthma that involved self-monitoring by peak expiratory flow or symptoms, connected with regular medical reviews and a written action plan, improved health outcomes of adults suffering from asthma [19]. It should be underlined, in the context of the Gibson et al. study [19], that McLean et al. [20] have presented different results based on a systematic review carried out in 2010 that included a completely randomised controlled trial of tele-healthcare initiatives aimed at improving asthma care. McLean et al. [20] showed that tele-healthcare interventions carried out for patients with relatively mild asthma rarely result in clinically relevant improvements in health outcomes, but they may be of certain importance for patients with a more severe disease who are at a high risk of hospital admission.
At the same time, Kruse et al. [21] indicated in a systematic review that patient portals show significant improvements in self-management of chronic disease and improve the quality of care. The authors suggest that thanks to a standard patient portal design that makes resources available and which can help in understanding and managing chronic conditions, health care organisations will be able to promote the adoption of patient portals [21].

The 'WikiBuild' portal created by Gupta et al. [22] is a perfect example of addressing patient expectations. Both physicians and patients, in particular patients suffering from asthma, can actively contribute to development of the portal. WikiBuild was tested as a collaborative design for an asthma self-management tool - the asthma action plan (AAP). AAP is an individualised written plan produced by a health care professional (HCP) for a patient with asthma in order to provide education and guidelines for self-management in the case asthma symptoms worsen. Gupta et al. [22] have shed new light on how wiki-inspired methods could involve patients and health care professionals in the development and use of an asthma action plan. The WikiBuild process proposes a daring new way of taking into account patient and professional preferences in the design of an action plan in order to increase its uptake [22, 23]. This type of solution should be considered an example of the functioning of healthcare system for every country - owing to the universal, almost unlimited access to the Internet and given the scale of the phenomenon of searching for health-related information online.

Due to a high percentage of persons searching for health-related information online, both in the general population and among patients, healthcare systems should endeavour to develop a global online collection of credible and scientifically proven health data. Online health education of patients can have a measureable impact on the healthcare systems as they may benefit from an online engagement of the patient in therapeutic and diagnostic processes. There is a need to create licensed Internet portals dedicated to health that would include scientifically proven information. These portals should compete with other online available information. The phenomenon commonly referred to as 'Dr Google' requires further study and analysis.

\section{Conclusions}

1. The number of individuals using the Internet for health purposes is very high, both in the reference group and in the group of patients 
suffering from chronic diseases (respectively: $92 \%$ and $97 \%$ ).

2. People suffering from respiratory allergy and/ /or asthma more often search for health-related information online on a monthly and weekly basis.

3. In both study groups, the diagnosis and physician recommendations are verified in conversations with close friends. But, people chronically ill verify the diagnosis on the Internet much more often, compared to the reference group.

4. The respondents in both study groups searched for health-related information online, despite having declared that they have not considered most information on health available online credible.

5. In both study groups the most common motives for searching for health-related information online are as follows: to find opinions about a physician the respondent is planning to see, and the need for self-treatment due to malaise, disease or complaint.

6. While searching for health-related information online, the respondents most often look for the information on the following issues: a specific disease, different methods of treatment of a given disease, specific medicines and opinions about physicians.

\section{Conflict of interest}

The authors declare no conflict of interest.

\section{References:}

1. The Public Opinion Research Center. The Communication of the study: Using the Internet. and retention. No. 92/2016, Warsaw 2016. http://www.cbos.pl/SPISKOM.POL/2016/K_092_16. PDF. Accessed 10 October 2016.

2. Polish Internet Research. Online services of health 2011. http:// pbi.org.pl/raporty/zdrowieserwisy.pdf. Accessed 10 October 2016.

3. Wolbring G, Lashewicz B. Home care technology through an ability expectation lens. J Med Internet Res. 2014; 16(6): e155, doi: 10.2196/jmir.3135, indexed in Pubmed: 24956581.

4. Hesse BW. The patient, the physician, and Dr. Google. Virtual Mentor. 2012; 14(5): 398-402, doi: 10.1001/virtualmentor.2012.14.5.stas1-1205, indexed in Pubmed: 23351206.

5. van der Eijk M, Faber MJ, Aarts JWM, et al. Using online health communities to deliver patient-centered care to people with chronic conditions. J Med Internet Res. 2013; 15(6): e115, doi: 10.2196/imir.2476, indexed in Pubmed: 23803284.

6. Stellefson M, Chaney B, Barry AE, et al. Web 2.0 chronic disease self-management for older adults: a systematic review.
J Med Internet Res. 2013; 15(2): e35, doi: 10.2196/jmir.2439, indexed in Pubmed: 23410671.

7. Byczkowski TL, Munafo JK, Britto MT. Family perceptions of the usability and value of chronic disease web-based patient portals. Health Informatics J. 2014; 20(2): 151-162, doi: 10.1177/1460458213489054, indexed in Pubmed: 24056751.

8. Kruse CS, Bolton K, Freriks G. The effect of patient portals on quality outcomes and its implications to meaningful use: a systematic review. J Med Internet Res. 2015; 17(2): e44, doi: 10.2196/jmir.3171, indexed in Pubmed: 25669240.

9. Pawankar R. Allergic diseases and asthma: a global public health concern and a call to action. World Allergy Organ J. 2014 $7(1)$ : 12 , doi: $10.1186 / 1939-4551-7-12$, indexed in Pubmed: 24940476.

10. Komorowski J. Epidemiology asthma in Poland based on test results ECAP. PhD Thesis, Medical University of Warsaw, Poland 2012.

11. Jenerowicz D, Silny W, Dańczak-Pazdrowska A, et al. [Non -allergic type of atopic dermatitis among patients of Allergic Diseases Diagnostic Center, University of Medical Sciences in Poznań]. Przegl Lek. 2005; 62(12): 1332-1336, indexed in Pubmed: 16786742

12. Procontent Communication. Report of a nationwide public opinion surveys on the image of Polish medicine 2016. http:// www.procontent.pl/pl/aktualnosci/. Accessed 19 Jan 2016.

13. Moretti FA, Oliveira VE, Silva EM. Access to health information on the internet: a public health issue? Rev Assoc Med Bras (1992). 2012; 58(6): 650-658, indexed in Pubmed: 23250092.

14. Kisilowska M, Jasiewicz J. Health information. Warsaw: Wydawnictwa Uniwersytetu Medycznego; 2013.

15. Heaivilin N, Gerbert B, Page JE, et al. Public health surveillance of dental pain via Twitter. J Dent Res. 2011; 90(9): 1047-1051, doi: 10.1177/0022034511415273, indexed in Pubmed: 21768306.

16. Duplaga M. The acceptance of e-health solutions among patients with chronic respiratory conditions. Telemed J E Health. 2013; 19(9): 683-691, doi: 10.1089/tmi.2012.0306, indexed in Pubmed: 23734700.

17. Bundorf MK, Wagner TH, Singer SJ, et al. Who searches the internet for health information? Health Serv Res. 2006; 41(3 Pt 1): 819-836, doi: 10.1111/j.1475-6773.2006.00510.x, indexed in Pubmed: 16704514.

18. Thackeray R, Crookston BT, West JH. Correlates of health -related social media use among adults. J Med Internet Res. 2013; 15(1): e21, doi: 10.2196/jmir.2297, indexed in Pubmed: 23367505 .

19. Gibson PG, Powell H, Coughlan J, et al. Self-management education and regular practitioner review for adults with asthma. Cochrane Database Syst Rev. 2003(1): CD001117, doi: 10.1002/14651858.CD001117, indexed in Pubmed: 12535399.

20. McLean S, Chandler D, Nurmatov U, et al. Telehealthcare for asthma. Cochrane Database Syst Rev. 2010(10): CD007717, doi: 10.1002/14651858.CD007717.pub2, indexed in Pubmed: 20927763.

21. Kruse CS, Argueta DA, Lopez L, et al. Patient and provider attitudes toward the use of patient portals for the management of chronic disease: a systematic review. J Med Internet Res. 2015; 17(2): e40, doi: 10.2196/imir.3703, indexed in Pubmed: 25707035 .

22. Gupta S, Wan FT, Newton D, et al. WikiBuild: a new online collaboration process for multistakeholder tool development and consensus building. J Med Internet Res. 2011; 13(4): e108, doi: 10.2196/jmir.1833, indexed in Pubmed: 22155694.

23. Archambault PM. WikiBuild: a new application to support patient and health care professional involvement in the development of patient support tools. J Med Internet Res. 2011; 13(4): e114, doi: 10.2196/imir.1961, indexed in Pubmed: 22155746. 